\title{
INTRODUCCIÓN A LA LITERATURA CUBANA
} tica) a trabajos sobre la identidad latinoamericana en Ensayos de otro mundo o $\mathrm{Ca}$ libán. Apuntes sobre la cultura en nuestra América. Entre sus numerosos libros de poesía, traducidos a varios idiomas, destacan Alabanzas, conversaciones, En su lugar, la poesía, Circunstancia y Juana y su último poemario Aquí.

\author{
ROBERTO FERNÁNDEZ RETAMAR
}

\section{Para Ambrosio Fornet}

En carta de noviembre de 1957 a la que acompañaba su libro $L a$ expresión americana, me dijo José Lezama Lima: «apostillas del umbral, mancha del pintorcete. Temas que son siempre introducciones. ¿Pero qué otra cosa puede escribir el hombre que no sea introducción?». Confieso que el recuerdo de esas palabras me dio algún sosiego cuando me puse a redactar las líneas que siguen. Porque tras recibir la invitación a participar en este curso, y aceptarla alegremente, me di cuenta de que una vez más me había metido en camisa de once varas. ¿Qué sería exactamente lo que se esperaba de mí? ¿La primera parte de un curso sobre literatura cubana? ¿O una apretada síntesis de su historia toda? ¿O el esbozo de los momentos más felices o significativos de ella? Después de desechar estas opciones, o mejor de desechar absolutizarlas, me vinieron a la memoria las palabras citadas de Lezama, y comprendí que, hiciese yo lo que hiciese, se trataría siempre de una introducción. En primer lugar, porque ello es lo que corresponde a la criatura humana, según el autor de La expresión americana; en segundo lugar, porque siendo estas páginas las iniciales del curso, es ocioso subrayar ese carácter; $y$, finalmente, porque me di cuenta de que soy casi un especialista en introducciones (a disciplinas, a temas, a obras, a figuras), la que se revela incluso en el título de varios de mis trabajos, y cuando no, en el contenido de muchos otros. Esto último sin duda ha sido tomado en cuenta por los sagaces organizadores del curso, guiados por el precepto dialéctico «zapatero a tus zapatos».
De todas formas, debo admitir que, sin desdeñar del todo las opciones arriba citadas, comenzará por lo que pudiéramos llamar algunas cuestiones generales en el desarrollo de la literatura cubana y sus circunstancias. Y si bien, como es lógico, destacará lo que creo que caracteriza a esa literatura, de ninguna manera puede esperarse que se trate de rasgos aplicables sólo a ella. Ese adanismo no es mi meta, como no puede serlo de nadie en sus cabales. Además, mencionará sólo a algunos autores, salvo una excepción al final; $y$, a no ser que lo considere absolutamente necesario, prescindiré de aludir a los asuntos que van a ser considerados por otros en el curso, y en cambio insistiré en los que no lo serán.

He aquí la primera verdad que voy a hacer mía y que abarca más allá de nuestra área. Al escribir sobre literatura peruana Mariátegui hizo observar algo que es válido para cualquier literatura similar: que "el 'nacionalismo' en la historiografía literaria [...] es un fenómeno de la más pura raigambre política, extraída a la concepción estética del arte». Decir de un texto que es bello es emitir un juicio estético; decir que es una novela, un juicio literario; pero decir que es cubano no es ni lo uno ni lo otro. Pues la categoría de «cubano» (como la de «español», «francés», "peruano» o «argentino») es de muy distinta naturaleza: no «geográfico-sentimental», como sugirió una vez con su gracia pendenciera, pero equivocado, Borges, sino histórica o si se quiere, política, tal como asegura Mariátegui, si a este último vocablo le damos su horizonte más vasto. Ciñéndonos a Cuba, no creo que estuviera pensando en Mariátegui ( $y$ mucho menos en el
Introducción a la literatura cubana ROBERTO FERNÁNDEZ RETAMAR 


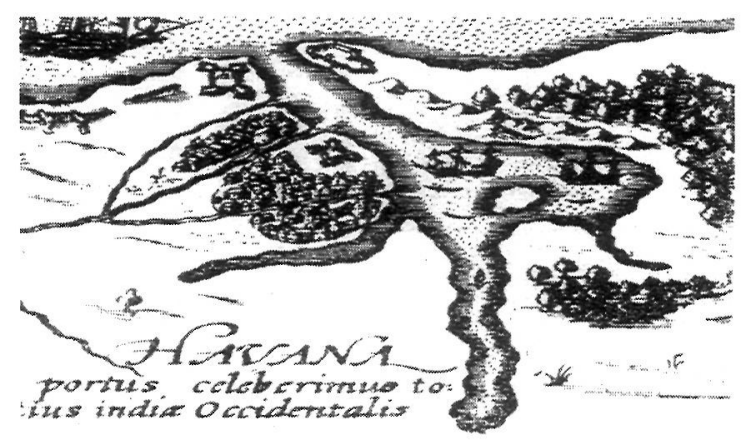

marxismo que aquél profesaba) Max Henríquez Ureña cuando, al frente del más apreciable Panorama bistórico de la literatura cubana que conozco, afirmó: «El desenvolvimiento de la vida literaria en Cuba está tan estrechamente ligado al de la historia política, que se hace imposible disociarlos». Y unas páginas después: «La historia literaria de Cuba representa, en sus líneas generales, el empeño constantemente renovado de lograr que el pueblo cubano adquiera plena conciencia de su destino histórico». Al hallarnos pues, en el orden literario, «en busca de nuestra expresión», para valernos de la fórmula clásica que propagara el hermano de Max, Pedro Henríquez Ureña, los cubanos, concientemente o no, perseguimos una expresión que no es sólo individual sino colectiva: perseguimos (con mayor o menor intensidad, con mayor o menor acierto) la consolidación de la colectividad que somos.

Otra generalidad, de área menos vasta: la literatura cubana, por obligación colonial en sus inicios, comienza como desprendimiento de la literatura española. Un desprendimiento, concretamente, de la literatura en lengua castellana, pues no creo que haya en la literatura cubana verdaderos destellos catalanes, ni gallegos, ni vascos. Por la comunidad lingüística, y por similitudes de otra naturaleza, hay que reconocer, sí, destellos canarios, de que será menester hablar a propósito del primer poema estimable escrito en Cuba que se conserva: Espejo de paciencia (1608), obra del canario Silvestre de Balboa.

En consonancia con lo anterior, las obras iniciales de la que iba a ser la literatura cubana fueron hechura de españoles. El primero, sin embargo, no la era, pues se trató del mesiánico y pintoresco genovés Cristóbal Colón, quien pergeñó las páginas inaugurales de que se tenga noticia sobre nuestra isla, páginas de previsible elogio, que hace unas décadas volvió a exaltar, entre tantos otros, nadie menos que Lezama. Sobre «las letras de Cuba antes de 1608» (fecha del poema Espejo de paciencia) dejó una erudita conferencia, que glosaré libremente, José Juan Arrom, quien después de mencionar el caso de los indígenas, sobre el que he de volver, concluye que desaparecieron sin dejar huellas; como tampoco produjo frutos literarios conservados el epidérmico contacto de españoles e indias, por lo que es necesario buscar el inicio de las letras cubanas en aquellas obras de navegantes, cronistas y colonos que se escriben en Cuba, tratan de Cuba o están íntimamente relacionadas con el desarrollo posterior de su cultura. Por descontado, se da aquí un sentido bien lato a la literariedad. Después del ejemplo ya mencionado del Diario de viaje de Colón, considerado piedra angular de las letras de Cuba, pasa a referirse a los cronistas de indias, encabezados por Las Casas, quien se entregó por completo a la tarea de defender, en lenguaje apasionado, el derecho del indígena a ser libre. El primer pasaje aducido es aquel en que narra la muerte del cacique Hatuey. Después de otros pasajes, se afirma que sería acto de justicia dar cabida en las letras cubanas a los escritos de Las Casas que atañen directamente a la isla y han fecundado a sus grandes escritores. Los otros autores aludidos no tienen la relevancia del Almirante ni del gran dominico. Pero el acucioso investigador no deja de rastrear más. A un oscuro licenciado Cabrera le atribuye lo que llama un «reportaje» de naufragios y tesoros robados, que sería incidente no desdeñable para una antigua novela de aventuras o un moderno folletín policíaco. Con criterios similares, el siglo XVI cubano puede ofrecer un muestrario, así sea magro, de cierta producción literaria. Pero, aparte de su despreocupación estética, se trata, sin duda, de una producción totalmente colonial, cuyos hacedores ni siquiera son cubanos. Y colonial seguirá siendo durante largo tiempo la literatura en Cuba. Lo que no es para sobresaltar. Alfonso Reyes ha dejado establecido que toda literatura colonial «[c]orresponde casi exactamente al concepto político, pero no del todo», y que «[e]l estado colonial es transitorio, y se encamina al estado de cultura como a una mayoría de edad».

La ya mencionada ausencia de areitos, ceremonias religiosas que practicaron los indígenas o incluían cantos y danzas, remite a la ausencia de los indígenas mismos, los cuales no sobrevivieron al impacto con los europeos. Sobre esto, Las Casas dejó vívidas páginas lancinantes. La sobrevivencia de los aborígenes sólo ocurriría en palabras, en particular en toponímicas (el mismo nombre del país es prue- 
ba de ello, pues resistió a otros como Juana y Fernandina), en la estructura de humildes viviendas llamadas bohíos, en alimentos, en costumbres como la del tabaco. Fueron vencidos de verdad y para siempre, no como en el caso del libro de Miguel León Portilla, Visión de los vencidos, ya que en el México actual (según lo recuerdan dramáticamente los sucesos de Chiapas), hay millones de descendientes de los visionarios a que se refiere el autor. En consecuencia, no hay en Cuba, paralelamente a la de origen español, una literatura indígena, así sea oral o amparada en disfraz español, como sí la hay, hasta nuestros días, en otros países americanos. Ejemplo señero de ello el del Perú, lo que ha merecido estudios bien valiosos de autores como Antonio Cornejo Polar y Martín Lienhard. Sin embargo, en el siglo XIX la memoria del extinguido indio (en especial el siboney) aparece en nuestras letras, sobro todo en nuestra poesía. Pero se trata de un recurso táctico, por lo general para objetar la colonización española, no de una auténtica reivindicación de quien ya no existía. Como una forma de rearticular la historia al margen de las etnias, y yendo más allá de Cuba, Martí escribirá a finales de ese siglo: «Se viene de padres de Valencia y madres de Canarias [fue su caso propio] y se siente correr por las venas la sangre enardecida de Tamanaco y Paramaconi, y se ve como propia la que vertieron por las breñas del cerro del Calvario, pecho a pecho con los gonzalos de férrea armadura, los desnudos y heroicos caracas». Y hace algo más de treinta años, Lezama dio al protagonista de su novela Paradiso el nombre de José Cemí: cemí se llamaba una imagen indocubana de destino religioso.

Caso bien distinto al del llamado indio es el del negro, «indígena 'importado'», según lo llamó en relación con zonas americanas más vastas Alejandro Lipschütz. Este otro «indígena» resultó elemento esencial para lo que iba a ser la cubanidad. En cuanto a lo literario, al no llegar a arraigar una de las distintas lenguas africanas traídas por los esclavos, el castellano acabó siendo su lingua franca: lo que, después de todo, les ocurrió también a los conquistadores y colonizadores, venidos de la Península y sus islas adyacentes, con el propio castellano, hecho que ya he mencionado. Por razones que desconozco (aunque sin duda fuertes emigraciones de ese origen, en determinado momento, pesaran en el hecho), en
Cuba, como en Argentina, a los descendientes de aquellos se les acabó llamando globalmente «gallegos», denominación que perduraría. (En uno de sus infrecuentes rasgos de humor, Martí dijo refiriéndose a una bailarina andaluza: « ¿cómo dicen que es gallega? / Pues dicen mal: es divina»). Así pues, en Cuba un catalán a un vasco estaba obligado a hablar castellano y a ser llamado gallego. El africano, por su parte, sería llamado negro (no obstante la variedad de sus orígenes étnicos), y obligado a expresarse también en castellano, aunque como lenguas rituales sobrevivieran varias, sobre todo el yorubá. Y en castellano dejaría ejemplos literarios como plegarias, leyendas, cuentos, refranes, originalmente producidos en lenguas africanas (así yorubá, ewe, bantú), que según don Fernando Ortiz fueron vertidos «al idioma amestizado y dialectal de los negros criollos» y sólo en este siglo iban a ser recogidos, en la estela de Ortiz, por autores como Ramón Guirao, Lydia Cabrera o Rómulo Lachatañeré. Mientras en pleno siglo XIX escritores negros o mestizos contribuían con obras de la literatura considerada «culta». Aquí es oportuno recordar que el de Cuba, en la denominación de Darcy Ribeiro, no es un pueblo «testimonio» (como los que cuentan con fuertes comunidades indígenas), ni un pueblo «transplantado» (como los que han sustituido a dichas comunidades por otras venidas de Europa), sino un pueblo «nuevo», en que todos sus componentes han venido de fuera (sobre todo de España y África), y conocerían un proceso que en 1940 Ortiz llamará «transculturación», y no ha concluido.

El primer centro de la América española estuvo en las Antillas, en la vecina isla de Santo Domingo. Pero el conocimiento de extraordinarios imperios del Continente desplazó hacia éste el interés metropolitano. Después de la conquista, hacia 1510 , y la fundación de las siete primeras villas, Cuba perdió su relativa preeminencia: de ella partieron, entre muchos aventureros que casi la dejaron despoblada, Hernán Cortés hacia la conquista de México (1519), y Hernando de Soto hacia la Florida (1539). Sólo entre 1516 y 1520 salieron de Cuba no menos de dos mil españoles en esas expediciones. A mediados de siglo, el número de personas libres se estimaba en seiscientos a setecientos; los indios, cerca de cien mil al empezar la conquista, no pasaban de cinco mil; los negros sumaban ya alrededor de
Introducción a la literatura cubana ROBERTO FERNÁNDEZ RETAMAR 


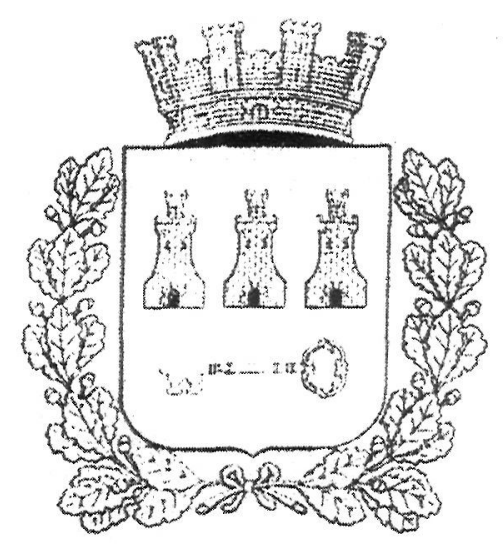

setecientos. La población tenía ya, pues, los caracteres de una típica factoría colonial, prevaleciendo los siervos y los esclavos. Aunque siguió trasvasando formas españolas por lo general asaz rudimentarias, quedó en efecto como menguada factoría, en que el sistema monopolista que España impuso a sus colonias sólo era roto por la piratería internacional y el frecuente contrabando. Precisamente en relación con estas últimos se produce la primera obra concientemente literaria producida en la Isla: el ya mencionado poema épico Espejo de paciencia, que data de 1608 y cuyas candorosas estrofas, escritas en la villa de Puerto Príncipe, tratan de un encuentro no de españoles e indios, como en La Araucana, de Alonso de Ercilla, sino de nativos y piratas. Su autor, Silvestre de Balboa Troya y Quesada, Era bastante enigmático para nosotros. Apenas se sabían sus fechas esenciales y que, habiendo nacido en las islas Canarias, estaba radicado en la Antilla mayor. Pero Cintio Vitier, cuidadoso editor de la pieza, me ha comunicado de viva voz un dato que a su vez le trasmitieron los hermanos Manuel y Eugenio Padorno, de dichas islas. En ellas, Balboa habría participado en la academia poética de Bartolomé Cairasco de Figueroa, quien mantenía relaciones con algunos clásicos de la lengua. El poema, pues, no es el resultado de una evolución literaria interna de que entonces carecíamos aún, sino el trasplante de un producto canario, adaptado a un tema y a aspectos ambientales del nuevo hogar del poeta. No se limitó a ello Balboa, sino que, a semejanza de aquella academia poética que conociera en su archipiélago atlántico, había atraído al cultivo de las letras a varios habitantes de la región, los cuales le dedicaron sendos sonetos laudatorios: de sus autores, tres habían nacido en la misma villa cubana. Sin entrar ahora en otros pormenores, vale la pena subrayar que tanto en el texto como en uno de los sonetos que lo preceden aparece el vocablo «criollo». Aquí de nuevo debo volver a Arrom, autor del mejor estudio que conozco sobre "Criollo: definición y matices de un concepto». Según tal estudio, el vocablo había nacido en el portugués del Brasil, de donde se difundiría por otras lenguas. Antes de concluir el siglo XVI, era común y corriente por todo el Nuevo Mundo, donde implicaba haber nacido allí, de ascendientes venidos del Viejo, sin importar el color de la piel, el estado político o la condición social. En efecto, en Espejo de paciencia, un blanco «mancebo galán» es llamado «criollo del Bayamo», y un negro, «Salvador criollo, negro honrado"; mientras Pedro de las Torres Cifuentes ofrece a Balboa un «soneto criollo de la tierra», donde no deja duda del carácter local del término: es «de la tierra». Se trata de un protoapunte en que lo cubano comienza lentamente a diferenciarse de lo europeo y lo africano. Recuérdese, de paso, que un importante personaje del jocundo Concierto barroco, de Alejo Carpentier, Filomeno, es presentado como «biznieto de un negro Salvador, que fue, un siglo atrás, protagonista de una tan sonada hazaña que un poeta del país, llamado Silvestre de Balboa, la cantó en una larga y bien rimada oda, titulada Espejo de paciencia...». Es curioso este deseo tanto de Lezama como de Carpentier de entroncar con el pasado insular en sus obras de ficción.

Pero la diferenciación entre «español»o «africano» y «criollo» no avanzará mucho más en Cuba hasta finales del siglo XVIII. La isla, mientras tanto, es avivada por la confluencia de las Flotas españolas que, de regreso a España cargadas de metales preciosos, hacen escala en La Habana. Para poder defenderla de piratas y corsarios, la ciudad es provista desde finales del siglo XVI con grandes fortificaciones que aún hoy despiertan la admiración de los turistas. Cuba suple así su carencia de oro y plata con su ubicación geográfica excepcional, que le ganará el epíteto de Llave del Nuevo Mundo, a la que pronto sumará algunos productos locales. La estancia de las Flotas y la construcción de fortalezas significan dinero y esclavos que se van traduciendo en el incremento de industrias incipientes: ganadería, azúcar, tabaco, maderas. Una clase formada por propietarios agrícolas nativos empieza a desarrollarse, se levantan residencias e iglesias de un suave barroquismo, se introduce la imprenta y se funda una Universidad, en La Habana. Las letras cubanas entre 1700 y 1790 (estudiadas en una buena monografía por Enrique Sainz) son harto discretas, e incluyen la pieza teatral El Principe jardinero y fingido Cloridano, obras de versificadores que merecerían ser destacados por Lezama en su singular Antología, de oradores eclesiásticos elogiados por Sainz y de los pri- 
meros historiadores de la isla: señal de una naciente autoconciencia.

La Época es sacudida por un acontecimiento mayor. En 1762 los ingleses, en guerra contra España, tomaron La Habana. Allí permanecieron un año, durante el cual el tráfico comercial fue muy intenso. El hecho puso a los cubanos en contacto estrecho con otras formas de vida, al mismo tiempo que los hizo conscientes de su importancia, y obligó a España a prestar más atención a Cuba. Sin embargo, en la defensa de La Habana, los héroes españoles y los criollos aún peleaban juntos. La nacionalidad cubana no estaba todavía diferenciada de la metropolitana. Incluso algunos años después los prohombres de la Isla seguirían considerándose «españoles de Ultramar».

Pero a la devolución de La Habana, que España cambió a Inglaterra por la Florida, va a sucederse una serie de hechos directa o indirectamente relacionados con Cuba, y causantes de su súbita transformación. Así, las modificaciones de la política colonial española, reflejo del despotismo ilustrado de Carlos III; la independencia de lo que serían los Estados Unidos; la Revolución Francesa, cuya repercusión en Saint Domingue (antes y después llamado Haití) y el bloqueo a que varias metrópolis someten al primer país independizado de nuestra América, arruinan su industria azucarera y permiten a Cuba asumir su papel; la sublevación de las colonias suramericanas, y la emancipación de los esclavos en las Antillas británicas. La circunstancia de contar con gobiernos alerta, como el de don Luis de Las Casas (1790-1796), permitió a Cuba propiciar los cambios necesarios, especialmente en cuanto a la importación de esclavos, para estar en condiciones de asumir el papel productor dejado vacante por Haití. Además, el auge creciente de los Estados Unidos ofrecía a los productores de la isla un mercado importante que pronto fue oficialmente tolerado por el gobierno español, enzarzado en nuevas guerras con Inglaterra y Francia.

Arrastrada al mercado capitalista mundial, Cuba fomentó su riqueza sobre bases deplorables: la esclavitud, que se multiplicó para poder hacer frente al creciente trabajo de la industria azucarera; y la concentración de tierras, que aunque no llegó a los desastres del latifundio moderno - el cual no fue posible sino hasta el arribo de grandes capitales estadounidenses - preparó su camino. Industrias como la tabacalera y la cafetalera fueron echadas a segundo sitio con el predominio del azúcar. La sacarocracia iniciaba su reinado. Sometida al régimen de plantaciones característico de las Antillas, Cuba se convertiría en la azucarera del planeta.

Sobre esta base, los criollos blancos dueños de plantaciones, que de «españoles de Ultramar» acabarían proclamándose cubanos, alcanzaron un estadio superior de existencia, que ha quedado cristalizado en la imagen que algunos europeos suelen hacerse de la vida en una rica colonia del trópico, y la franco-cubana condesa de Merlín presentó en su obra $L a$ Havane (1844). El ferrocarril fue introducido en 1037, antes que en España, y vinculado a las exigencias de la industria azucarera. Se crearon instituciones sociales y culturales, se construyeron teatros, avenidas y suntuosas residencias. «Durante este período» pudo decir el historiador estadounidense Leland $\mathrm{Ha}$ milton Jenks, «fue Cuba la colonia más rica del mundo. En muchos aspectos de cultura material y artística llegó a sobrepasar a España». Una de las empresas intelectuales de la época, la Revista Bimestre Cubana (18311834), era, a los ojos de Pedro Henríquez Ureña, «la mejor revista literaria, por entonces, de todos los países de lengua española, sin excluir a España».

Este instante cubano se inicia en torno a 1790. Más de uno ha dicho que el siglo XIX alborea para Cuba ese año, en que se inicia el gobierno de don Luis de Las Casas, aparece, con su patrocinio, el que sería el órgano iluminista y neoclásico del patriciado cubano del momento, El Papel Periódico de la Havana [sic] (que durará con ese nombra hasta 1805), y es ya evidente la transformación de lo que fue una factoría en una colonia de plantaciones en vías de contradictoria modernización. Casi imperceptiblemente empieza a asomar la contradicción colonia/metrópoli, que al principio se manifiesta, tímidamente, en rasgos locales, elogios a las frutas del terruño debidos a poetas como Manuel de Zequeira y Arango en su «Oda a la piña», o en diálogos entre las frutas europeas y las nuestras, como en la «Silva cubana» atribuida a Manuel Justo de Rubalcava: son apenas barruntos de diálogos que encontrarán interlocutores mucho más dramáticos que el aguacate y la pera. Pero para
Introducción a la literatura cubana ROBERTO FERNÁNDEZ RETAMAR 


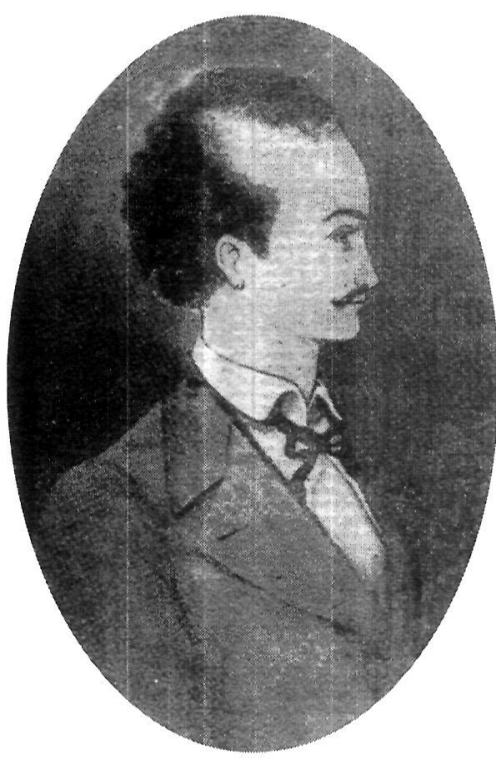

Gabriel de la Concepción Valdés, «Plácido». esa clase emergente, tal contradicción habrá de ser sofocada durante décadas por otra: la contradicción esclavistas/esclavos. No es extraño, por ello, que al estallar la revolución hispanoamericana de independencia a partir de 1810 - una revolución del patriciado frente a España-, Cuba no se sumara al proceso secesionista. La oligarquía criolla, que se tiene por blanca y aspira a convertir al país en una nación moderna (hoy diríamos que de capitalismo desarrollado), aunque llega a desear el poder políti$\mathrm{co}$, tiene fundados temores de que una revolución pudiera arrastrar tras sí las grandes dotaciones de esclavos y transformar el sentido de la guerra, como había ocurrido en Haití. Tal oligarquía no va más allá de una actitud reformista que encarna con triste lucidez el activo y moderado Domingo del Monte, una de las principales cabezas culturales, quien confesó que pagaban el delito de tener esclavos siéndolo ellos mismos.

Las dos contradicciones metrópoli/colonia, esclavistas/esclavos van a recorrer buena parte del siglo XIX (aunque la esclavitud fue abolida por los insurrectos en 1868, tardó en serlo por España hasta 1886), y se expresarán enérgicamente en el pensamiento y las letras del país. Sólo los independentistas se hallaban dispuestos a zanjar ambos dilemas. Para reformistas (partidarios de permanecer unidos a una España que en vano querían políticamente flexible) y anexionistas (quienes veían la solución en incorporarse a unos Estados Unidos entonces esclavistas), la esclavitud resultaba, a la vez, fuente de riqueza y dogal. Y en las primeras décadas de ese siglo eran escasos los intelectuales independentistas. Mencionaré a los dos más destacados. (Ellos, además, son los primeros creadores de gran nivel de los géneros reyes de nuestras letras, si aceptamos para Cuba que dichos géneros, como Ángel Rama dijo en relación con toda Hispanoamérica y es criterio que comparto, son la poesía y el ensayo, los cuales, a juzgar por los títulos de las conferencias, serán poco tratados en el curso en lo que toca al siglo XIX; y tampoco lo será mucho el ensayo en el siglo XX). Me refiero ahora a José María Heredia y Félix Varela. Al hablar de cada uno, añadiré algo sobre el desarrollo de los géneros respectivos hasta las vísperas del fin del siglo pasado.

Significativamente, Heredia y Varela son los más destacados intelectuales cubanos de su tiempo, y al abrazar el independentismo, desbordan las posibilidades de su clase de origen en ese momento, lo que los obligará al destierro. El más joven de ellos, Heredia, es también de extraordinaria precocidad. Antes de los nueve años hace versos; a los diecisiete, ya es uno de los mejores poetas vivos del idioma: entonces escribe el primer texto mayor de la poesía cubana, «En el teocalli de Cholula»; a los diecinueve años, conspira por la libertad de su patria y se ve obligado a exiliarse; vivió en adelante en Estados Unidos y México, donde murió. A diferencia de poetas cubanos que lo precedieron, Heredia no es un mero inventarista de la naturaleza insular: su rebeldía y su poder de descripción, su cultura y su nostalgia interiorizan el paisaje insular, lo funden al sentimiento de una peculiaridad nacional que vemos asomar en sus versos de arte mayor, mientras escribe los iniciales poemas políticos del país. De Manuel Pedro González en adelante se lo ha considerado nuestro primer poeta romántico. Canta al mar, al Niágara, a la tempestad, a la libertad, al amor, a las ruinas, en cálidas estrofas en las que la tradición española es visiblemente enriquecida no sólo por una firme educación clásica, sino por nuevas voces francesas, inglesas, italianas. Martí, que lo juzgó admirablemente y lo llamó el primer poeta de América, decía que en sus versos aprendió a ser cubano. Pues en su poesía Heredia sella el sentimiento de singularidad del cubano, y fija los símbolos de su tradición, palma o estrella. Opuesto tanto al régimen metropolitano como al crimen de la esclavitud, es un parricida no sólo en lo que toca a España, sino a su clase, la cual, atemorizada, abandona a este precoz heraldo de cubanía, pero reconociéndole su genio literario, que también se manifestó en piezas dramáticas, cuentos y críticas. Al morir en 1839, a sus treinta y cinco años, era indiscutible que $\mathrm{Cu}$ ba perdía a su primer gran hombre de letras.

Convenimos en considerar ya abiertamente nuestra inicial generación romántica la de los poetas Gabriel de la Concepción Valdés, Plácido, y José Jacinto Milanés. Plácido, artesano mulato, es la primera figura notable de nuestras letras en no ser blanca ni provenir, consecuentemente, de las clases adineradas. 
Aunque sin su jerarquía literaria, fue antecedido por un hombre singular: Francisco Manzano, esclavo de gran talento que al cabo será manumiso por Del Monte y su grupo. A pesar de su origen, ninguno de los dos produce obra poética en que se exprese su condición social ni la tragedia de su raza. Su poesía se acomoda a los esquemas criollos blancos, que van separándose de los propiamente españoles. En cambio Manzano nos ha dejado un documento con escasos pariguales en cualquier sitio: el relato de su propia vida, la autobiografía de un esclavo negro en la Cuba esplendorosa y atroz de aquellos años. Tanto Plácido como Manzano fueron involucrados por los gobernantes españoles en la Conspiración de la Escalera - llamada así debido al tipo de tormento al que se sometía a los inculpadosen 1843-1844, con la que se quiso castigar a las numerosas revueltas de negros y mestizos, sofocar el desarrollo de una incipiente pequeña burguesía de aquéllos, y en general atemorizar a los criollos. Plácido fue fusilado, y Manzano dejado en libertad, pero queriendo que se lo olvidara no volvió a escribir una línea más.

Milanés representa una intelectualidad criolla ya en abierta pugna con España. Anticolonialista, antiesclavista, no proviene del patriciado; por el contrario, modesto empleado de provincia, es la encarnación de una pequeña burguesía radicalizable, destinada a un papel revolucionario en nuestra historia. Poeta romántico de intenso eticismo, con frecuencia mezcla a sus notas de delicada ternura (en que el paisaje de Heredia se hace más suave) alusiones abiertas a la libertad y a la independencia; o desarrolla temas nativistas que alcanzarán su cima con la generación siguiente. También escribió piezas teatrales, ellas no alcanzaron la envergadura de las de su coetánea Gertrudis Gómez de Avellanada, extraordinaria autora en verso y prosa que se disputan Cuba y España.

Aunque la segunda generación romántica prolongaría muchas actitudes anteriores, sus dos notas más características son el desarrollo de una poesía nativista que se vale con frecuencia de la exaltación del desaparecido indígena; y el acendramiento de la lírica. Entre otras figuras de menor calidad, lo primero será realizado sobre todo por Juan Cristóbal Nápoles Fajardo, El Cucalambé, que sigue siendo el poeta más popular en nuestros campos. Entregado a la descripción de la vida en dichos campos con fines nacionalistas, anticolonialistas, dio con una expresión genuina y llevó a su cima una línea de criollización de la poesía española iniciada a principios de siglo. Esa poesía había conocido, casi paralelamente, dos propulsores mayores: uno, de extracción popular, Francisco Poveda, El Trovador Cubano; y otro, rico exponente del patriciado, el ya nombrado Domingo del Monte. Ninguno de ambos era un gran poeta, pero sus obras nos permiten asistir a una curiosa mutación de funciones de las formas Poéticas. Del Monte, conservador tanto en lo político como en lo literario, al proponerse una poesía criollista, recurre al romance, la estrofa tradicionalmente popular en España, pero no en Cuba, no obstante valerse Del Monte de asuntos campesinos cubanos; Poveda, hombre más elemental en su formación y auténtico campesino, se atiene a la espinela o décima, que a pesar de su origen culto había venido aclimatándose en los campos de Cuba y otros países americanos, al punto de hacerse la forma habitual, hasta nuestros días, de las improvisaciones del campesino o guajiro, correspondencia cubana de las improvisaciones del payador rioplatense. En las décimas de El Trovador Cubano, de El Cucalambé, de numerosos poetas anónimos (cuyas obras no empezarían a recogerse hasta que Samuel Feijoo lo hiciera en 1961) se anunció, y se despedazó, un posible Martín Fierro insular.

La otra nota valiosa del período está dada por un conjunto de poetas en que se afina la sensibilidad romántica. Aunque esta línea es iniciada por Rafael María de Mendive, maestro de Martí, el nombre descollante de esta etapa es el de Juan Clemente Zenea, una de las voces más transparentes y puras de la poesía cubana, quien expresará en nocturnos y elegías la desazón de un poeta delicado a quien su deber empuja al combate y que no logra estar siempre a la altura de las circunstancias. Como Plácido, murió fusilado por los españoles. Su estancia, desterrado, en los Estados Unidos, le permitió familiarizarse con la literatura de aquel país, sobre la que escribió estudios que parecen haber influido en Bécquer, cuyas Rimas aparecieron el año del fusilamiento del cubano. Con la obra de Zenea se suele empa-
Introducción a la literatura cubana ROBERTO FERNÁNDEZ RETAMAR 


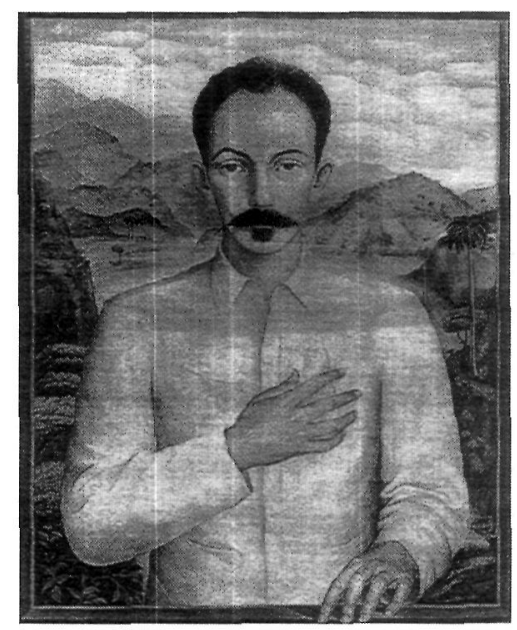

José Martí, en un óleo de Jorge Arche (1943). rentar la de la intensa elegíaca Luisa Pérez de Zambrana, mientras Joaquín Lorenzo Luaces produjo una poesía más diversa, donde a ratos se anuncia el parnasianismo, y cultivó también el teatro. Al estallar en 1868 la primera parte de la guérra de independencia, apuntaba una nueva generación que tendrá como tarea histórica fundamental dicha guerra, y luego se manifestará en otros géneros (meditativos, críticos), de preferencia a la poesía. Con esta generación, el romanticismo se extingue como fuerza creadora en nuestra poesía. Otra época comienza, durante las últimas décadas del siglo, en toda Hispanoamérica: la encabeza el llamado modernismo, que en Cuba tendrá dos altos representantes en José Martí y Julián del Casal. Martí, precisamente en el obituario que dedicó a Casal, ofreció en 1893 la mejor definición del aún discutido modernismo, que él no nombró así:

en América está ya en flor la gente nueva, que pide paso a la prosa y condición al verso, y requiere trabajo y realidad en la política y en la literatura. Lo hinchado pasó, y la política huera y rudimentaria, y aquella falsa lozanía de las letras que recuerda los perros aventados del loco de Cervantes. Es como una familia en América esta generación literaria, que principió por el rebusco imitado, y está ya en la elegancia suelta y concisa, y en la expresión artística y sincera, breve y tallada, del sentimiento personal y del juicio criollo y directo.

Las dos vertientes principales de la poesía martiana son la de sus «versos libres» y la de sus «versos sencillos». Los primeros, que sólo aparecerán póstumamente, en 1913, son endecasílabos sin rima, con encabalgamientos ásperos y violentas imágenes de filiación barroca. Uno de los primeros en conmoverse ante estos poemas fue Unamuno, quien los comparó a los salmos hebraicos y a Whitman: al parecer, ellos influyeron en su Cristo de Velázquez. La otra vertiente de la poesía de Martí comprende las dos obras que publicó: Ismaelillo, donde injertó las rápidas visiones de la poesía moderna (entre cuyos fundadores estuvo, como destacó Rama) en las formas de los villancicos tradicionales; y su libro de plena madurez, Versos sencillos, algunos de cuyos poemas, con un reconquistado sabor popular de coplas americanas, se han cantado en el mundo con la tonada de La guantanamera (tonada que para Carpentier es la de un romance traído por los conquistadores), lo cual no puede hacer olvidar la insondable complejidad de su sencillez, que preludia notas machadianas.

La otra figura notable del modernismo en Cuba, el doliente Julián del Casal, representa el costado del movimiento que fue más visible en sus primeros momentos, con fuerte impronta de parnasianos y simbolistas franceses. Dejó discípulos que se vincularían a la guerra reiniciada en 1895, en uno de cuyos primeros combates murió Martí.

Dejando atrás la poesía de Cuba en el siglo XIX, entremos en otra área. Si Heredia fue el inicial gran hombre de letras del país, al presbítero Félix Varela le correspondió rango similar en lo que toca al pensamiento: José de la Luz y Caballero, maestro mayor, lo llamó «el primero que nos enseñó a pensar». Pero no compete ahora detenernos en esa esencial faena suya, que por otra parte le costó vivir lejos del país, debido al inconmovible independentismo al que arribó; murió en los Estados Unidos, por cierto el mismo año, 1853, en que murió Del Monte y nació Martí. Lo que voy a destacar es un juicio emitido sobre él por José Antonio Portuondo, quien en su Boceto bistórico de las letras cubanas afirmó: «En la obra de Varela es tan constante la preocupación por los problemas políticos y sociales que ha hecho olvidar sus méritos extraordinarios de escritor, a pesar de que su Miscelánea filosófica (1819) lo revela como uno de los mejores ensayistas de nuestra lengua». Lo notable de esta cita estriba en que Portuondo, que fue un crítico cuidadoso, hablara de «ensayistas» refiriéndose a una obra de principios del siglo XIX, cuando el ensayo, como género, tardaría aún bastante en ser reconocido en nuestra lengua toda, no obstante los ilustres precedentes extranjeros que se remiten a Montaigne, acuñador del propio vocablo. Lo que, desde luego, no quiere decir que no se practicara en español, pero sí que no tenía nombre ni perfil definido. El juicio de Portuondo incita a que estudiemos la posible existencia de ensayos, incluso en el ámbito reducido de la literatura cubana, al menos desde el siglo XVIII. Puestos a conjeturar, se debe atender también el caso de otros géneros.
Introducción a la literatura cubana ROBERTO FERNÁNDEZ RETAMAR 
Por ejemplo, Cintio Vitier, Fina García Marruz y Roberto Friol, compiladores de la antología La literatura en el Papel Periódico de la Havana, reunieron los materiales de su selección en los acápites "Crítica y polémica», «Cuentos», «Poesía» y «Teatro». El primer acápite, presentado por García Marruz, ¿no contiene algunos de nuestros primeros ensayos, varios de ellos atribuidos al Padre José Agustín Caballero? El segundo acápite no deja lugar a la duda: su presentador, Roberto Friol, asegura que el cuento cubano nació allí, con lo que contradice otras hipótesis. Y más allá de dicha compilación, aunque el testimonio es para muchos un género de este siglo, de estas décadas (sólo en 1970 fue convocado un premio de testimonio, por la Casa de las Américas), ¿no son testimonios muchas de las obras de los cronistas de Indias?; ¿no Es un testimonio la Excursión a Vueltabajo, de Cirilo Villaverde?; y en trabajo reciente, Michèle Guicharnaud-Tollis pudo establecer un paralelo entre la autobiografía de Manzano y una obra clásica del testimonio contemporáneo: Biografía de un cimarrón, de Miguel Barnet.

Baste lo anterior para no incurrir en el fetichismo de los géneros; $y$, de momento, volver a los ensayos, todavía sin ese nombre. Si Varela llamó a varios de los suyos Miscelánea filosófica, José Antonio Saco (quien había dirigido la Revista Bimestre Cubana) agrupó un vasto conjunto de los debidos a su pluma en tres volúmenes de Papeles sobre Cuba. No todos ellos son ensayos; pero muchos sí, y están escritos en una prosa vibrante y ardiente de polemista. Saco, además, acometió la redacción de una enorme Historia de la esclavitud que aun inconclusa sigue siendo uno de los monumentos de la cultura cubana. Es significativo que sus Papeles los dedicara a la memoria de Domingo del Monte, señal inequívoca de su identificación con el gran animador de la cultura cubana, reformista como Saco y enemigo como él de la esclavitud. Saco, si bien quería hacer cesar la trata y abolir la esclavitud, consideraba que la nacionalidad cubana (a la cual defendió con vigorosa tenacidad frente a los anexionistas) era asunto de blancos, y propugnó por ello el blanqueamiento del país, una de sus obsesiones, lo que ha hecho que se le compare con Sarmiento. Sus admoniciones $\mathrm{y}$ advertencias no fueron tomadas en cuenta por el gobierno español, que lo obligó a vivir en el destierro, donde murió (como Varela,
Heredia, Del Monte). Fue, según Portuondo, «la voz más alta del patriciado»; su obra, «el examen más agudo y perdurable de las raíces de nuestra nacionalidad». Después de él, sólo serían posibles las revolucionarias, que acabarían situando en el eje del país a sectores medios y populares con voceros como Antonio Macea y José Martí.

Entiendo que la conferencia «Literatura y pensamiento en el fin del siglo XIX» considerará a otras de nuestras importantes ensayistas de la centuria: pienso en autores como $\mathrm{Ma}-$ nuel Sanguily, Enrique José Varona y, sobre todo, el mayor de nuestros escritores, Martí. Mientras, evidentemente, la «Narrativa cubana del siglo XIX» se hará cargo de lo que anuncia. Tendremos así un cuadro de lo fundamental de nuestras letras en un siglo del que hay que decir que si se inició en 1790 , concluyó, desastrosamente por partida doble, en 1898. En ese año, la intromisión estadounidense en la guerra entre España y Cuba (que había recomenzado en 1895), no sólo venció a ambas, hecho en verdad infrecuente, sino que convirtió a la segunda en tierra ocupada militarmente, y luego en protectorado y neocolonia, hasta 1958, ejerciendo el poder por lo general a través de gobiernos títeres.

Mirando retrospectivamente a la literatura cubana de la centuria pasada, sendas observaciones llaman la atención, una desde la derecha y otra desde la izquierda. La primera es de don Marcelino Menéndez y Pelayo, según el cual «el espíritu general de los literatos y de los hombres de ciencia en Cuba ha solido ser sistemáticamente hostil a España y manifestarse francamente como tal». La segunda es de Martí, cuya obra estuvo tan nutrida no sólo de literaturas extranjeras, sino de lo mejor de los clásicos de su idioma; lo cual no le impidió decir, aludiendo a su contemporaneidad, que «los pueblos de habla española nada, que no sea manjar rehervido, reciben de España». El siglo había separado a las literaturas de ambos países, como había separado a los países mismos, no obstante permanecer políticamente unidos. Pero a partir de 1898 las cosas no seguirían siendo así.

En el siglo XX se ha puesto el énfasis del curso, y apenas me es necesario añadir gran cosa. Como ya adelanté, sin embargo, echo de menos una conferencia que abordara en conjunto su ensayo. No pienso suplirla (entre otras cosas, porque carezco de tiempo),
Introducción a la literatura cubana ROBERTO FERNÁNDEZ RETAMAR 
pero no quiero desaprovechar la oportunidad para señalar, a propósito de tal ensayo, un par de cosas. La primera, la nueva relación que en este siglo se establecería entre la exmetrópoli y la ex-colonia. Quizá el ejemplo inicial sonado la ofrezca el libro de ensayos de don Fernando Ortiz Entre cubanos... Psicología tropical, aparecido en 1913 y encabezado por dos cartas a Unamuno, cuya huella es visible en toda la obra, al extremo de que ella fue señalada por Carlos Serrano como ejemplo de "regeneracionismo trasatlántico». En la segunda de aquellas cartas, Ortiz le asegura al rector salmantino: «y es que $\mathrm{Cu}$ ba, en no pocos aspectos, es más española que España». En trabajo más serio sobre el tema, de 1940, «Los factores humanos de cubanidad», Ortiz volverá a citar con identificación a Unamuno.

Unamuno dejará su huella en varias generaciones de ensayistas cubanos. Ortega y Gasset habrá de hacerlo sobre todo en integrantes de la generación que empezó a manifestarse en la tercera década, como fue el caso destacado de Jorge Mañach (en su coetáneo y contradictor Marinello, las raíces españolas miran más a los barrocos). Y María Zambrano, en la generación posterior, sobre todo en el grupo que se nucleó en torno a la revista Orígenes: Vitier y García Marruz se contaron entre sus discípulos. A propósito de ese grupo, aunque no suele recordarse como debiera, las conferencias que García Lorca ofreció en La Habana en 1930 (en especial la que dedicó a la imagen poética en don Luis de Góngora) estimularon la ensayística deslumbrante de Lezama. Menciono lo anterior tan sólo como muestras de la presencia española en nuestro ensayo del siglo. Más allá del ensayo, es sabido que Juan Ramón, García Lorca, Alberti, Aleixandre, Cernuda y otros poetas españoles también se hicieron sentir en la poesía cubana. El final desdichado de la guerra civil española interrumpiría por largo tiempo esa fértil relación. Pero ese es otro cantar.

Lo segundo que diré a propósito del ensayo cubano de esta centuria tiene ver con el tratamiento de determinadas cuestiones que es propio del género. Si en el siglo pasado el ensayo había considerado problemas entonces en discusión, otro tanto hará éste. Sólo que los problemas, desde luego, no serán ya los mismos. A la contradicción metrópoli/colonia le ha sucedido la de metrópoli/protectorado o neocolonia (siendo ahora la metrópoli no España, sino los Estados Unidos); a la contradicción esclavistas/esclavos, la que opone a la viceburguesía o burguesía desnacionalizada (la cual ocupó el sitio de la clase que perdió su oportunidad histórica al finalizar la Guerra de los Diez Años, en 1878, y cuyo epitafio fue el Pacto del Zanjón) y a los sectores medios y populares que ascendieran a primer plano en la Guerra de 1895, con un ideario revolucionario diseñado por Martí. Truncada aquella guerra en 1898, su proyecto quedó como una «revolución pospuesta», según dijera el historiador Ramón de Armas. El siglo XX será atravesado por tales contradicciones, $\mathrm{y}$ muchos de sus ensayistas se harán cargo de ellas. Se trata de un entramado complejo que apenas puedo rozar aquí. En general, conscientes de la condición capitidisminuida del país, los ensayistas de la primera generación republicana, sobre todo los reunidos en torno a la inicial revista importante del siglo, Cuba Contemporánea, defienden la nación frente a la prepotencia estadounidense, pero sin asumir una posición fuerte ni una perspectiva clasista popular. Entre quienes irán más lejos en aquella generación habrán de contarse el propio Ortiz, José Antonio Ramos y Emilio Roig de Leuchsenring. Corresponderá a la segunda generación hacer frente a las contradicciones con todo su fuego. Varios de sus integrantes redescubren, deslumbrados, a Martí. Julio Antonio Mella y Rubén Martínez Villena introducen el marxismo en el pensamiento cubano, y lo aplican creadoramente a desentrañar nuestros problemas. Mella aporta el primer análisis marxista de Martí; y Martínez Villena escribe Cuba, factoría yanqui, paralelamente a los Siete ensayos de Mariátegui. Intelectuales como ellos, como muchos de quienes se expresaron en, la heterogénea revista Social, en la vanguardista Revista de Avance y en la más fugaz y radical América Libre, habían formado parte desde 1923 del Grupo Minorista, inclinado a la izquierda, al que de modo sorpresivo le apareció entre sus filas un fascistizante: Alberto Lamar Schweyer. Su libro Biología de la democracia, después de algunas escaramuzas, provocó, como réplica, una «Declaración» del Grupo que en 1927 redactó Martínez Villena y fue, paradójicamente, el canto de cisne de dicho Grupo. El país, impulsado por el rechazo al régimen tiránico de Gerardo Machado, iba a tratar de acome- 
ter la «revolución pospuesta». Como consecuencia de ello, los más agudos editores de Revista de Avance (que se extingue en 1930), Mañach y Marinello, acabarán separándose, asumiendo el primero posiciones conservadoras, y sumándose el segundo al comunismo. Al cabo, la revolución vuelve a ser pospuesta: para 1935, se ha ido «a bolina», según dijera años después Raúl Roa, uno de nuestros más apasionados ensayistas políticos. El país entraba en otro período oscuro y corrupto, con la nueva tiranía, intermitente, de Batista, que regresa al poder con el golpe de Estado de 1952. Al año siguiente, el 26 de julio de 1953 , Fidel Castro y sus jóvenes compañeros asaltan dos cuarteles en Oriente, y vuelven a intentar la «revolución pospuesta». El autor intelectual, declara Fidel, es Martí; su programa, $L a$ historia me absolverá. Después de conocidas luchas épicas, el primero de enero de 1959 la revolución, al fin, llega al poder. Cuba alcanza su independencia, e inicia una transformación profunda que asume carácter socialista y pronto cumplirá cuarenta años.

Doy por sentado que el curso presentará lo realizado durante ese lapso en varios géneros. El ensayo predominante será sobre todo político e histórico, pero abordará también otras áreas. Lo ejercen figuras de varias generaciones: Marinello, Roa, Carpentier, Portuondo, Mirta Aguirre, Carlos Rafael Rodríguez, Julio Le Riverend, Lezama, el Manuel Moreno Fraginals de El ingenio, Vitier, García Marruz, Tomás Gutiérrez Alea, Julio García Espinosa, Ambrosio Fornet, Edmundo Desnoes, Jorge Ibarra, Lisandro Otero, Leonardo Acosta, Graziella Pogolotti, Rine Leal, Miguel Barnet, Nancy Morejón, Ana Cairo, Víctor Casaus, Joel James, Desiderio Navarro, Rogelio Martínez Furé, Fernando Martínez Heredia, Pedro Pablo Rodríguez, Raúl Hernández Novás, Luis Toledo Sande, Abel Prieto, Rosa Ileana Boudet, Nara Araújo, Rafael Hernández, Luisa Campuzano, Francisca Ló- pez Sacha, Margarita Mateo, Jorge Luis Arcos, Arturo Arango, Enrique Ubieta, yo (no me queda más remedio que citarme, para no parecer coqueto, así como a mi compañera Adelaida de Juan), muchos y muchas más. Una figura adquiere relieve mundial: el Che. En los últimos años, además de revistas ya existentes, como Casa de las Américas y La Gaceta de Cuba, se han creado otras destinadas a acoger ensayos nuevos: Temas y Contracorriente son ejemplos de ellas. Algunos permanecen al margen de la discusión política, como Severo Sarduy, Julio Rodríguez Luis, Roberto González Echevarría, Emilio Bejel. Y, por supuesto, no han faltado ensayistas hostiles a la Revolución, con frecuencia tránsfugas, también con frecuencia continuadores (en pleno auge del imperialismo estadounidense y del «pensamiento único» de derecha) de los anexionistas del siglo pasado, cuando no émulos de Lamar Schweyer. Equivalen a «los que no tienen fe en su patria», los «letrados artificiales», ornados de «falsa erudición», que fustigó Martí en Nuestra América.

Voy a concluir esta introducción pensando en lo que brota, y reiterando algo que dije hace treinta años, al final de una charla sobre antipoesía y poesía conversacional en Hispanoamérica que me solicitó Mario Benedetti:

No conviene olvidar el carácter pendular del arte [...]. Hay muchos rasgos que nosotros no podemos prever en estos momentos y que es posible que engendren una poesía [en esta ocasión debemos decir: una literatura] de la que no tenemos noción. El arte, como la historia toda, según decía Marx, suele tomar el otro camino, «Esa otredad que padece lo uno», de que hablaba Antonio Machado, puede estar ahora mismo oyendo la conversación, y ella va a decir la última palabra. Que, desde luego, no será la última. 